\title{
The Effect of Sex Education on Teenage Pregnancy among Secondary School Students in Ibadan Metropolis.
}

\author{
Odekunmi Funke Beatrice \\ Depertment of General Studies, Ogun State College Of Health Technology, Ilese-Ijebu Ogun State.
}

\begin{abstract}
Unplanned pregnancies among Nigerian teenagers and young women have risen despite improvements in educational levels. Though, over the same period the use of modern contraceptive methods among sexually active adolescent women in Nigeria had changed, yet this has not slowed down the rate of teenage pregnancy among the adolescents in Nigeria. The study utilized the survey research method using a self report questionnaire to gather the data. The revalidated Adolescent Sex Education And Teenage Pregnancy Questionnaire was used in the study. There is no significant influence of sex education received on teenage pregnancy $\left(X^{2}=1.203, d f=1, p>.05\right)$. However there was significant relationship between contraceptive and the sex education received. $\left(X^{2}=38.931, d f=5, p<.05\right)$. It was recommended that appropriate education regarding sexual health and socio-cultural practices need to be included in the school curriculum and sexual education in the public, private secondary schools, NGO and HIV/AIDS intervention programmes.
\end{abstract}

Key words: Sex education, Teenage pregnancy.

\section{Introduction}

With the more relaxed sexual standards of modern times, teens are becoming sexually active at younger ages. Sex education and teenage pregnancies are concepts deeply linked with each other. The task of instructing adolescents about sex has been seen as the responsibility of the parents. But parent-child communication in sexual matters may be hindered by parental inhibitions or by various intergenerational tensions, and studies have shown that children rarely receive their first information on sexual matters from their parents (Encarta, 2007). The battle has always been between sex education and abstinence-only. Some experts argue that abstinence education is the only way to prevent teenagers from having sex, while others insist that teenagers will have sex no matter what, and it is better for them to be equipped with solid educational information about sex. Such will enable them to limit HIV infections and prevent many unplanned teen pregnancies (Guttmacher Institute, 2008).

Pam Lehman (2008), stated that Sex education becomes important to teens because, teen pregnancies are associated with serious health concerns for both mother and child. Complications of pregnancy, miscarriage, stillbirth, premature birth and low birth weight, birth defects and disabilities are more likely in teen pregnancies. In addition to physical health risks, teen parents generally have a less optimistic future than peers who are not teen parents. Long term effects for children of teen pregnancies include lower academic achievement, have less successful careers, and more likely to live in poverty and a tendency to become teen parents themselves Pam Lehman (2008).

The problem of teenage pregnancy is considerably worse in Nigeria than in any other developing country. Among developing countries, Nigeria has one of the highest birth rates for women less than 20 years and Study suggested that the problem of teen pregnancy in Nigeria may be related to less sex education in schools and lower availability of birth control services and supplies to adolescents, Encarta (2007). Since sex education found its way into the Nigerian school system the emphasis has been impacting moral lesson and social value to secondary school students, although some have voiced out that sex education increases sexual activity Encarta (2007). Sex education has not yielded much success in Nigeria since its introduction in the secondary school curriculum as more adolescents get pregnant and drop out of school.

However, effective sex education programs can decrease sexual activity and increase contraceptive use among those already sexually active. They maintain a narrow focus on reducing specific sexual risk-taking behaviours; provide accurate information about sexuality; build interpersonal and communication skills to resist sexual pressures; address both social and media influences on sexual behaviours, (Amazigo et al 2003). Therefore this study seeks to investigate the impact of sex education on adolescent pregnancy among secondary school pupils.

\subsection{Theoretical Orientation}

Biology has long been considered a key factor in explaining adolescent sexual behaviour. Several researchers have described the role of biological 'unfoldment', including physical forces such as pubertal 
development and hormones, in adolescent sexual behaviour, suggesting that the timing of sexual activity may be as much a biological issue as a social or behavioural one (Miller and Fox, 1987; Miller et al, 2001; Kotchick et al, 2001; Udry, 1988). Miller et al (2001) point out that recent research has found links between genes, hormone levels, and the developmental point at which adolescents begin to engage in sexual intercourse. (Udry and Billy, 1987; Udry et al, 1986; Udry, 1988) found evidence that levels of androgen hormones longitudinally influenced the debut of sexual intercourse of males, as well to the level of sexual motivation, though not the sexual act itself, in adolescent females.

\subsection{Factors influencing adolescent's sexual behaviour}

Families are an incredibly important influence on the behaviour of any child in many ways. For instance, low family socio economic status has been repeatedly linked to risky adolescent sexual behaviour (Ramirez-Valles et al, 1998; Kotchick et al, 2001). Numerous studies have also demonstrated that living with both biological parents is related to increased age of sexual debut (Taris and Semin, 1997; Ramirez-Valles et al., 1998; Upchurch et al, 1999).

Parental control and monitoring have been repeatedly linked to lower levels of risky adolescent sexual behaviour, usually, it is thought, by reducing the amount of opportunity available to engage in premarital sexual behaviour (Luster and Small, 1994; Small and Luster, 1994; Hovell et al., 1994). Parental warmth or support has also been found to relate to adolescent sexual behaviour (Miller et al, 2001). Luster and Small (1994) found that highly supportive parents had adolescents at much lower risk for having more than one sexual partner and inconsistently using contraception.

Fisher (1989) found that more communication with parents teens perceive as liberal was related to females engaging in more sexual behaviour, and communication between conservative parents and sons led to sons being more conservative themselves. Similarly, according to Moore et al (1986), higher levels of communication with liberally perceived parents was related to sons engaging in more sexual behaviour, while communication between conservative parents and daughters was related to less risky sexual behaviour.

Another contextual factor which has been shown to influence adolescent sexual behaviour is the media. L'Engle, Brown and Kenneavey (2006) found that more exposure to sexually related media and media that conveys an approval of adolescent sexual behaviour was related to higher levels of intention to engage in sexual behaviour and a greater amount of sexual behaviour in general. This effect persisted even after controlling for other contextual factors including parents, peers, school, and religious influences.

Close friends and peers have been found to be quite important to the socio sexual development of adolescents (Smith et al, 1985; Christopher, et al, 1993). Association with deviant peers was related to an increased risk of adolescents engaging in a number of problematic behaviours, including risky sexual behaviour (Ary et al, 1999; Metzler et al,1994).

\subsection{Study population}

\section{Methods}

The target population of this research is secondary students in Ibadan metropolis, the capital of Oyo state in south-western Nigeria. It has eleven local governments within the metropolis.

\subsection{Sample and instrument}

The sample size used for the study was two hundred and thirty (250) respondents. Due to the fact that the study is focusing on a specialized population (Adolescents) purposive sampling method was adopted. The instrument used for data collection was the questionnaire. The questionnaire for this research was divided into two parts. The first part included the socio-demographic characteristics of the respondents. The second part composed of general questions to ascertain the experiences of the students on sex education and their sexual behaviour.

\section{Results and Discussion}

Table 1 revealed that $\mathbf{4 2 . 5 \%}$ of the respondents were males while $\mathbf{5 7 . 5 \%}$ were females

Table 1 sex

\begin{tabular}{lll}
\hline & Number & Percentage \\
\hline Male & 152 & 42.5 \\
Female & 198 & 57.5 \\
\hline
\end{tabular}


Table 2 shows $25.6 \%$ of the respondents were within age group of $10-13$ years, $69.6 \%$ were within $14-16$ years, while $4.8 \%$ were within the age bracket of $17-19$ years.

Table 2 Age

\begin{tabular}{lll}
\hline & & \\
\hline $\mathbf{1 0}-13$ years & 64 & 25.6 \\
$\mathbf{1 4}-16$ years & 174 & 69.6 \\
$\mathbf{1 7}-19$ years & 12 & 4.8 \\
\hline
\end{tabular}

Table 3 reveals that $82.4 \%$ of the respondents claimed to be Christians while $17.2 \%$ were of the Islamic faith and $0.4 \%$ identified with the other religions.

Table 3 Religion

\begin{tabular}{lll}
\hline & & \\
\hline Christian & 206 & 82.4 \\
Muslim & 43 & 17.2 \\
Others & 1 & 0.4 \\
\hline
\end{tabular}

Table 4 shows $85.2 \%$ of the respondents lived with both parents, $6 \%$ of them lived with their mothers only, $4.8 \%$ ) of the respondents lived with their fathers, $2.8 \%$ of the respondents were living with their step parents, $1.2 \%$ of them claimed to be living with their relations.

Table 4 Guardian

\begin{tabular}{lll}
\hline & & \\
\hline Parents & 213 & 85.2 \\
Mother only & 15 & 6 \\
Father only & 12 & 4.8 \\
Step Parent & 7 & 2.8 \\
Relation & 3 & 1.2 \\
\hline
\end{tabular}

Table 6 shows that $32.5 \%$ of the respondents' father were Civil Servants, $35.0 \%$ indicated that their fathers were Traders, $27.1 \%$ respondents fathers were Military Personnel, $2.5 \%$ of the respondents said that their fathers were Self-Employed. However, $18.9 \%$ of the respondents' mothers were Civil Servants, $52.5 \%$ indicated that their mothers were Traders, $1.1 \%$ respondents mothers were Military Personnel, $25.7 \%$ of the respondents said that their mothers were Self-Employed, and 1.8\%)indicated that their mothers were working with Private Organizations.

Table 6 Occupation

\begin{tabular}{lllll}
\hline Occupation & & Father & & \multicolumn{2}{c}{ Mother } \\
\hline & Number & Percentage & Number & Percentage \\
Civil Servant & 91 & 32.5 & 53 & 18.9 \\
Trader & 98 & 35 & 147 & 52.5 \\
Military Personnel & 76 & 27.1 & 3 & 1.1 \\
Artisan & 7 & 2.5 & 72 & 25.7 \\
Private Organisations & 8 & 2.9 & 5 & 1.8 \\
\hline
\end{tabular}

Table 7 shows parental educational level, $37.6 \%$ of fathers had only secondary school education, $16.4 \%$ of fathers had OND, $5.6 \%$ of fathers had degree, $4.4 \%$ of fathers had post graduate Diploma and $26 \%$ of fathers had second degree. However, 48.\% of mothers had secondary school education, 4.4\% of mothers had OND/NCE, $8 \%$ of mothers had Degree, $12.8 \%$ of mothers had PGD and $9.3 \%$ of mothers had second degree qualifications.

Table 7 Educational levels of the respondent's guardian

\begin{tabular}{lllll}
\hline Educational Level & Father & & & Mother \\
\hline & Number & Percentage & Number & Percentage \\
SSCE & 119 & 37.6 & 120 & 48 \\
OND/NCE & 41 & 16.4 & 11 & 4.4 \\
B.Sc & 14 & 5.6 & 20 & 8 \\
PGD & 11 & 4.4 & 32 & 12.8 \\
M.Sc & 65 & 26 & 27 & 9.3 \\
\hline
\end{tabular}

Majority of the adolescents $60.8 \%$ preferred the school sex education as a first source of information compared to $39.20 \%$ who considered have their parents as the first most preferred source of information on sex 
education. While older sibling, peer group, media and health workers are other preferred sources of sex education as seen in table 8 .

Table 8 Source of sex education

\begin{tabular}{lll}
\hline Source of Sex Educationn & Number & Percentage \\
\hline School & 60.8 \\
Parent & 39.2 \\
\hline
\end{tabular}

About $32 \%$ of the adolescents reported that issues pertaining to positive relationships such as mutual respect and open communication were discussed, while $15.2 \%$ disagree that issues pertaining to positive relationships such as mutual respect and open communication were discussed while $52.8 \%$ cannot remembered whether such issues were discussed.

Table 9 Perception of Respondent to Quality Sex Education

\begin{tabular}{lllll}
\hline $\begin{array}{l}\text { Perception of Respondent to Quality Sex } \\
\text { Education }\end{array}$ & Number & Percentage \\
\hline $\begin{array}{l}\text { Positive } \\
\text { Respect }\end{array}$ & & & & 32 \\
No & & & 30 & 15.2 \\
Not Sure & & 132 & 52.8 \\
\hline
\end{tabular}

Table10 shows the benefit of education revealed that only $23.2 \%$ reported benefiting from the sex education programme. $2.4 \%$ reported not benefiting from the sex education while $74.4 \%$ did not give any response. Table 10 Benefits of Sex Education Program

\begin{tabular}{lll}
\hline Benefits of Sex Education Program & Number & Percentage \\
\hline Yes & 58 & 23.2 \\
No & 6 & 2.4 \\
Not Sure & 184 & 74.4 \\
\hline
\end{tabular}

Majority of the respondents (45.6\%) reported not having no sex partners, $40.4 \%$ have one sex partners, $5.2 \%$ have two or three, $4.8 \%$ four to five sexual partners and $4 \%$ have more than five sexual partners. This shows that majority of the adolescents have sexual partners as seen in table 11 .

Table 11 Number of Sex Partners

\begin{tabular}{lll}
\hline Number of Sex Partners & Number & Percentage \\
\hline None & 114 & 45.6 \\
$\mathbf{1}$ & 101 & 40.4 \\
$\mathbf{2}-\mathbf{3}$ & 13 & 5.2 \\
$\mathbf{4}-\mathbf{5}$ & 12 & 4.8 \\
$>\mathbf{5}$ & 10 & 4 \\
\hline
\end{tabular}

Table 12 shows that $12.4 \%$ used some form of protection always, $6.4 \%$ used it somewhat often, $16.4 \%$ use protection occasionally, $6.8 \%$ use protection sometimes, $6 \%$ rarely use protection and $52 \%$ never used it before.

Table 12 Contraceptive Use

\begin{tabular}{lll}
\hline Contraceptive Use & Number & Percentage \\
\hline Always & 31 & 12.4 \\
Somewhat Often & 16 & 6.4 \\
Occasionally & 41 & 16.4 \\
Rarely Use & 15 & 6.8 \\
Never Used it Before & 130 & 52 \\
\hline
\end{tabular}

The result revealed that condom is the most widely used prevention among the adolescents $(38.8 \%), 17(6.8 \%)$ use birth control pills, $8(3.2 \%)$ use diaphragm and $72(28.8 \%)$. however $56(22.4 \%)$ did not give the type of birth control method they utilized.

Table 13 Types of contraceptive used

\begin{tabular}{lll}
\hline Types & Number & Percentage \\
\hline Condom & 97 & $38.8 \%$ \\
Pills & 17 & 6.7 \\
Diaphragm & 8 & 3.2 \\
Noprotection & 72 & 28.8 \\
Not specific & 56 & 22.4 \\
\hline
\end{tabular}


Table 14 showed that about $29.6 \%$ of the respondents reported that they have been pregnant before while $70.4 \%$ had never been pregnant before.

Table 14 Incidence of pregnancy

\begin{tabular}{lll}
\hline Incidence of pregnancy & Number & Percentage \\
\hline Yes & 74 & 29.6 \\
No & 176 & 70.4 \\
\hline
\end{tabular}

Table 15 revealed that $70.4 \%$ reported never getting pregnant compared to $25.2 \%$ who had got pregnant once before and $4.4 \%$ who had gotten pregnant two or more times.

Table 15 Number of occurrence of pregnancy.

\begin{tabular}{lll}
\hline Number of occurrence & Number & Percentage \\
\hline Never got pregnant & 176 & 70.4 \\
Once & 63 & 25.2 \\
Twice and more & 11 & 4.4 \\
\hline
\end{tabular}

The result of the Chi-square test revealed that there was no significant relationship between teenage pregnancy and the sex education received. The result showed that there was no difference in the ratio of those who received sex education and got pregnant to those who did not receive sex education $\left(\mathrm{X}^{2}=1.203\right.$, $\mathrm{df}=1$, $\mathrm{p}>.05)$.

\section{Decision rule:}

The calculated Pearson chi square value $\left(\mathrm{X}^{2}\right.$ calc $\left.=1.203\right)$ was not significantly higher than the table value $\left(\mathrm{X}^{2} \mathrm{Tab}=1.203\right)$ at the level 0.05 level of significance. This means that the null hypothesis is accepted while the alternate hypothesis is rejected that there is no significant relationship between teenage pregnancy

This finding suggests that the sex education received in schools does not have any significant effect on the level of teenage pregnancy. This findings is in line with the study of Bonellet et al (2003) which revealed that sex education becomes less effective because of socioeconomic disadvantage and dislike of school. Those disliking school were more likely to have sexual intercourse, expect sexual intercourse by age 16, and expect to be parents by the age of 20. Oettinger (1999) also supports this study that enrollment in sex education was associated with earlier sexual activity for females. Sex education also was associated with earlier pregnancy for some groups of females, though these effects were smaller and not always statistically significant

\section{Hypothesis 2}

Ho: There will be no significant influence of sex education programme on the contraceptive use

$\mathrm{H} 2$ : There will be significant influence of sex education programme on the contraceptive use

In other to test the hypothesis, chi square test for independence analysis on the cross tabulation of the response on "whether adolescent received sex education from school and whether the adolescent utilize contraceptive or any form of protection during sexual encounters.

The result of the Chi-square test revealed that there was no significant relationship between contraceptive use and the sex education received. The result showed that adolescents who received sex education significantly reported more contraceptive use compared to those without sex education.

\section{Decision rule:}

The calculated Pearson chi square value $\left(\mathrm{X}^{2}\right.$ calc $\left.=38.931\right)$ was significantly higher than the table value $\left(\mathrm{X}^{2} \mathrm{Tab}=1.203\right)$ at the level 0.05 level of significance. This means that the null hypothesis is rejected while the alternate hypothesis is accepted. There is significant relationship between contraceptive and the sex education received.

This findings is also confirmed by Oettinger (1999) that sex education had some causal impact on teen sexual behavior, by providing information that enabled teens to alter the risks of sexual activity. Reid (1982) also corroborate this findings that education has a favourable influence on knowledge and attitudes, but little direct effect on sexual behaviour. Unintended teenage pregnancies are probably caused more by lack of anticipation than by simple ignorance.

\section{Conclusion}

The results of this investigation on incidence of teenage pregnancy among adolescents in Ibadan metropolis revealed the reality of the teenage pregnancy in the area of study. The adolescent preferred information from parents, medical practitioners, and sexual clinics compared to that from any other source. Though the level of sex education is considerably high, what is evident is that the sex education available is not 
good enough to address the problems of teenage pregnancy in the region. The result demonstrated that there is high rate of teenage pregnancy among the adolescents sampled in this study. Thus more is needed to be done regarding the type and quality of sex education in Nigeria. Evidently, lack of quality sex education plays a significant prominent role in the perpetration of this social problem. . A comprehensive sex education is the type that will emphasize the value of abstinence, but also to provide teenagers with the tools and knowledge that are more likely to lead to more responsible behavior should they decide to have sex at all.

\section{Recommendations}

Paucity of human and material resources has undermined efforts to redress this social malady. The implication of this result is that the parents need to do more in giving sex education to their children as more children prefer to be taught by their parents. More also medical practioners and sexual clinics should be involve in giving sex education to children as more students also prefer this source of information to other sources. According to American Psychological Association (2005) teens that have parents who are diligent in instilling their values and expectations in their children are more likely to wait to have sexual intercourse, and to have it less often and exercise some safety.

\section{References}

[1]. Amazigo U, Silva N, Kaufman J, Obikeze DS. 2003. Sexual activity and contraceptive knowledge and use among in-school adolescents in Nigeria.

[2]. Ary, D.V., Duncan, T.E., Biglan, A., Metzler, C.W., Noell, J.W. and Smolkowski, K. (1999). Development of Adolescent Problem Behavior. Journal of Abnormal Child Psychology,27, 141-150.

[3]. Christopher, F.S., Johnson, D.C. and Roosa, M.W. 1993. Family, Individual, and Social Correlates of Early Hispanic Adolescent Sexual Expression. Journal of Sex Research, 30, 54-61.

[4]. Fisher, T.D. 1989. An Extension of the Findings of Moore, Peterson, and Furstenberg 1986 regarding Family Sexual Communication and Adolescent sexual Behavior. Journal of Marriage and the Family, 51, 637-639.

[5]. Guttmacher Report on Public Policy. Guttmacher Institute. Retrieved on 2007-05-23.

[6]. Hovell, M., Sipan, C., Blumberg, E., Atkins, C., Hofstetter, C.R., \& Kreitner, S. 1994. Family Influences on Latino and Anglo Adolescents' Sexual Behavior. Journal of Marriage and the Family, 56, 973-986.

[7]. Kotchick, B.A., Shaffer, A., Miller, K.S. and Forehand, R. 2001. Adolescent Sexual Risk Behavior: A Multi-System Perspective. Clinical Psychology Review, 21, 493-519.59

[8]. Luster, T. and Small, S.A. 1994. Factors Associated with Sexual Risk-Taking Behaviors among Adolescents. Journal of Marriage and the Family, 56, 622-632.

[9]. Metzler, C.W., Noell, J., Biglan, A., Ary, D, and Smolkowski, K. 1994. The social context for risky sexual behavior among adolescents. Journal of Behavioral Medicine, 17(4), 419- 438.

[10]. Miller, B.C., \& Fox, G.L. 1987. Theories of Adolescent Heterosexual Behavior. Journal of Adolescent Research, 2, $269-282$.

[11]. Miller, B.C., Benson, B., \& Galbraith, K.A. (2001). Family Relationships and Adolescent Pregnancy Risk: A Research Synthesis. Developmental Review, 21, 1-38.

[12]. Moore, K.A., Peterson, J.L., and Furstenberg, F.F. 1986. Parental Attitudes and the Occurrence of Early Sexual Activity. Journal of Marriage and the Family, 48, 777-782.

[13]. Ramirez-Valles, J., Zimmerman, M.A., \& Newcomb, M.D. 1998. Sexual Risk Behavior among Youth: Modeling the Influence of Prosocial Activities and Socioeconomic Factors.Journal of Health and Social Behavior, 39, 237-253.

[14]. Small, S.A.and Luster, T. 1994. Adolescent sexual activity: An ecological, risk-factor approach.Journal of Marriage and the Family, 56, 181-192.

[15]. Smith, E.A., Udry, J.R., and Morris, N.M. 1985. Pubertal Development and Friends: A Biosocial Explanation of Adolescent Sexual Behavior. Journal of Health and Social Behavior, 26,183-192.

[16]. Taris, T.W. and Semin, G.R. 1997. Parent-Child Interaction During Adolescence, and theAdolescent's Sexual Experience: Control, Closeness, and Conflict. Journa l of Youth andAdolescence, 26, 373-398.

[17]. Udry, J.R. (1988). Biosocial Predispositions and Social Control in Adolescent Sexual Behavior.American Sociological Review, 53, 709-722.

[18]. Udry, J.R. and Billy, J.O.G. 1987. Initiation of Coitus in Early Adolescence. American Sociological Review, 52 , 841-855.

[19]. Udry, J.R., Talbert, L.M., \& Morris, N.M. 1986. Biosocial Foundations for Adolescent Female Sexuality. Demography, 23, 217230 .

[20]. Upchurch, D.M., Aneschensel, C.S., Sucoff, C.A. and Levy-Storms, L. 1999. Neighborhood and Family Contexts of Adolescent Sexual Activity. Journal of Marriage and the Family, 61,920-933. 